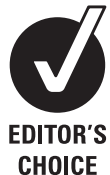

1 Department of Neurology, Erasmus MC-University Medical Centre Rotterdam, Rotterdam, The Netherlands ${ }^{2}$ Dementia Research Centre, UCL Institute of Neurology, London, UK

${ }^{3}$ Department of Neurology, VU University Medical Centre Amsterdam, Amsterdam, The Netherlands

\section{Correspondence to}

Dr John C van Swieten, Erasmus MC-University Medical Center Rotterdam, Department of Neurology, Room Hs 611, 's-Gravendijkwal 230, 3015 CE Rotterdam, The Netherlands;

j.c.vanswieten@erasmusmc.n

Received 17 March 2010 Accepted 1 September 2010 Published Online First 22 October 2010

\title{
Clinical, genetic and pathological heterogeneity of frontotemporal dementia: a review
}

\author{
Harro Seelaar, ${ }^{1}$ Jonathan D Rohrer, ${ }^{2}$ Yolande A L Pijnenburg, ${ }^{3}$ Nick C Fox, ${ }^{2}$ \\ John C van Swieten ${ }^{1}$
}

\section{ABSTRACT}

Frontotemporal dementia (FTD) is the second most common young-onset dementia and is clinically characterised by progressive behavioural change, executive dysfunction and language difficulties. Three clinical syndromes, behavioural variant FTD, semantic dementia and progressive non-fluent aphasia, form part of a clinicopathological spectrum named frontotemporal lobar degeneration (FTLD). The classical neuropsychological phenotype of FTD has been enriched by tests exploring Theory of Mind, social cognition and emotional processing. Imaging studies have detailed the patterns of atrophy associated with different clinical and pathological subtypes. These patterns offer some diagnostic utility, while measures of progression of atrophy may be of use in future trials. $30-50 \%$ of FTD is familial, and mutations in two genes, microtubule associated protein tau and Progranulin (GRN), account for about half of these cases. Rare defects in VCP, CHMP2B, TARDP and FUS genes have been found in a small number of families. Linkage to chromosome 9p13.2-21.3 has been established in familial FTD with motor neuron disease, although the causative gene is yet to be identified. Recent developments in the immunohistochemistry of FTLD, and also in amyotrophic lateral sclerosis (ALS), have led to a new pathological nomenclature. The two major groups are those with tau-positive inclusions (FTLD-tau) and those with ubiquitin-positive and TAR DNA-binding protein of $43 \mathrm{kDa}$ (TDP-43) positive inclusions (FTLD-TDP). Recently, a new protein involved in familial ALS, fused in sarcoma (FUS), has been found in FTLD patients with ubiquitin-positive and TDP-43-negative inclusions. In this review, the authors discuss recent clinical, neuropsychological, imaging, genetic and pathological developments that have changed our understanding of FTD, its classification and criteria. The potential to establish an early diagnosis, predict underlying pathology during life and quantify disease progression will all be required for diseasespecific therapeutic trials in the future.

\section{INTRODUCTION}

Frontotemporal dementia (FTD) is the second most common early-onset dementia and is characterised clinically by progressive behavioural changes and frontal executive deficits and/or selective language difficulties. Although recognised over a century ago, the last few years have seen rapid advances in our understanding of FTD, its genetic causes and pathological substrates. ${ }^{1-5}$ In 1892, Arnold Pick described a patient with progressive aphasia and lobar atrophy, ${ }^{6}$ and in 1911, the presence of argyrophilic neuronal inclusions at neuropathological examination, later known as 'Pick bodies', was reported by Alois Alzheimer. ${ }^{7}$

The selective involvement of the frontal and/or temporal cortices with relative preservation of more posterior cerebral regions determines the presentation, and gives rise to the terms FTD as a clinical syndrome with distinct subtypes, and the term frontotemporal lobar degeneration (FTLD) to describe the pathological syndrome. The disease progresses from an insidious onset of behavioural change or language impairment and cognitive decline to a severe and more generalised dementia, accompanied by progressive cerebral hypometabolism and atrophy of frontal and temporal lobes preferentially.

The clinical spectrum of FTD encompasses distinct canonical syndromes: the behavioural variant of FTD (bvFTD) and the language variants, semantic dementia (SD) and progressive non-fluent aphasia (PNFA). There is also overlap of FTD with motor neuron disease (FTD-MND or FTD-ALS), as well as the parkinsonian syndromes, progressive supranuclear palsy (PSP) and corticobasal syndrome (CBS). ${ }^{8}$ Recent advances in FTD have identified novel genetic defects and a chromosomal locus in hereditary forms of FTLD, ${ }^{9-14}$ as well as novel neuropathological associations, for example the proteins TAR DNA-binding protein of $43 \mathrm{kDa}$ (TDP-43) and fused in sarcoma (FUS) are now recognised in the pathological classification of FTLD. ${ }^{15-19}$

In this review, we will discuss the different clinical variants, neuropsychological aspects, neuroimaging, hereditary forms, pathological subtypes and clinicopathological associations of FTD with the focus on recent developments.

\section{EPIDEMIOLOGY}

The exact prevalence of FTD remains uncertain, as there have been only a few studies, and these have produced a wide range of estimates. The highest prevalences have been reported from two independent studies in the UK and one Italian study with an estimated prevalence of FTD of 15-22 per 100000 inhabitants aged 45-64 years, ${ }^{4} 520$ which was almost half the prevalence of $\mathrm{AD}$ in this age group. ${ }^{5}$ However, a study from The Netherlands estimated the prevalence of FTD to be significantly lower (9.4 per 100000 in the age group of $60-69$ years). ${ }^{21}$ The lower prevalence relative to $\mathrm{AD}$ in that series is consistent with some pathological series. ${ }^{22} 23$ The estimated prevalence in a Swedish population-based sample of 85-year-olds was 3.1 per 100 inhabitants. $^{24}$ 
Two reported incidence studies of FTD were remarkably consistent: 3.5 and 4.1 cases per 100000 person-years in the agegroup of 45-64 years. ${ }^{25} 26$ There do not appear to be any clear gender differences in susceptibility. 21232627

The average age at onset is around 50-60 years, although approximately $10 \%$ have an age at onset of over 70 years (up to 89 years). ${ }^{9}$ There is a wide range in durations of illness (2-20 years) partly reflecting different underlying pathologies. Patients with FTD-MND have the shortest survival with a mean of 3 years. ${ }^{28}$

\section{CLINICAL PRESENTATION}

BvFTD, SD and PNFA all share an insidious onset and inexorably progressive but variable decline. Each clinical syndrome is associated with topographically distinct cerebral involvement: with bvFTD associated with symmetrical (or right-sided) frontal and anterior temporal dysfunction, PNFA left frontotemporal dysfunction and SD anterior temporal (typically left more than right) deficits. BvFTD is the most common of these subtypes and accounts for about half of all cases ${ }^{9}{ }^{29}$ without any clear differences in presentation between sporadic and familial bvFTD, or between late- and early-onset bvFTD. ${ }^{30}$ While all of the subtypes can occur in conjunction with motor neuron disease (FTD-MND), it is most commonly seen with bvFTD, occasionally with PNFA and only very rarely with SD.

Emotional blunting, loss of empathy, apathy, selfishness and neglect of personal hygiene are typical of bvFTD but may be seen in all subtypes. ${ }^{31}$ Other frequently reported symptoms are disinhibition, irritability, gluttony, altered preference for foods (particularly for sweets), wandering, pacing, motor and verbal stereotypies, and hoarding. ${ }^{31}$ It has been suggested that bvFTD can be subdivided into apathetic and disinhibited variants depending on initial presentation ${ }^{32}$; however, these symptoms frequently co-occur, and the usefulness of this distinction is questionable. $^{30}$ A stereotyped-compulsive syndrome has been recognised as a third variant. ${ }^{33}$

A significant correlation with specific topographic patterns of atrophy, hypoperfusion or hypometabolism has been found for several of these symptoms. Apathy is associated with atrophy and dysfunction of the right anterior cingulate cortex and superior frontal gyrus, ${ }^{34}$ disinhibition with the right subgenual cingulate cortex and orbitofrontal cortex, ${ }^{34-36}$ overeating with an orbitofrontal-striatal circuit, ${ }^{37}$ and executive dysfunction with the dorsolateral and prefrontal cortex. ${ }^{38}$

The core features of current clinical criteria for bvFTD encompass an insidious onset and gradually progressive course, early disruption of social and personal conduct, early emotional blunting and lack of insight. ${ }^{2} 3$ Stereotypic behaviour, alterations in eating behaviour and loss of social awareness particularly support a diagnosis of FTD, while more posterior symptoms such as difficulty with spatial orientation and locating objects suggest Alzheimer's disease (AD). ${ }^{31} 3940$ Apathy, mood changes and dysexecutive symptoms occur in both and have not been found to be effective discriminators of FTD from AD. ${ }^{39} 4142$

The clinical criteria focus on behavioural changes rather than cognitive disturbances, and therefore might apply equally to a number of psychiatric syndromes, including (late-onset) depression and schizophrenia. However, virtually no studies have focused on the differentiation of bvFTD from psychiatric disorders. With this in mind, an interesting group of patients is the 'non-progressive', 'benign' or 'slow' bvFTD, who do not (or only slowly) progress over time, and do not show definite structural atrophy or hypometabolism many years from symptom onset. ${ }^{43-45}$ Behavioural symptoms may appear to progress according to carer description but without any measurable cognitive change. ${ }^{45}$ As these patients with a nonprogressive bvFTD appear to have a normal life expectancy and seldom come to autopsy, the underlying pathology is still unknown. ${ }^{44} 45$ Possible diagnoses that have been suggested include decompensated Asperger syndrome or personality disorder, mild bipolar syndrome, or an otherwise previously undescribed neuropsychiatric syndrome with functional disruption of the same orbitofrontal-amygdala-polar network. $^{44}$

Autopsy-proven studies have shown that the current clinical criteria correctly classify approximately $80-90 \%$ of bvFTD cases, whereas $3-17 \%$ are pathologically proven $\mathrm{AD}{ }^{46-49}$ However, the criteria lack sensitivity (37\%) in the early phase of bvFTD. ${ }^{50}$ Therefore, revised criteria for bvFTD have been proposed in light of recent advances. ${ }^{51}$ The most important revisions are the incorporation of neuroimaging and genetic findings within the criteria and expansion of the role of supportive behavioural features for the diagnosis of bvFTD. ${ }^{51}$

The nosology of the language variants of FTD remains controversial. PNFA and SD are the canonical subtypes of what is collectively often termed primary progressive aphasia (PPA). Fluent speech, progressive impairment of single-word comprehension, preserved articulatory abilities and a multimodal breakdown of semantic memory are the characteristic features of SD. ${ }^{52}$ Patients with SD may show behavioural changes in the course of the disease similar to bvFTD. ${ }^{53}$ In particular, they may become egocentric and develop fixed daily routines. ${ }^{53}$ PNFA patients present with apraxia of speech and/or expressive agrammatism: single-word comprehension and object knowledge are relatively preserved, and behavioural symptoms are less common. However, there are patients with progressive language impairment who do not fit into the SD and PNFA: a third, more recently defined, subtype of PPA is the logopenic or phonological variant (LPA) which is characterised by a slow rate of speech output, word-finding difficulties, deficits in sentence repetition and occasional phonemic errors in spontaneous speech and naming, whereas motor speech, expressive grammar and singleword comprehension are relatively spared. ${ }^{52} 54$ It remains unclear whether there are further subtypes of PPA, although there is some evidence that patients with GRN mutations have a non-fluent PPA syndrome distinct to either PNFA or LPA. ${ }^{55}$

PPA subtypes have an association with different types of underlying pathology. SD is associated most commonly with FTLD-TDP type $1^{17}$ pathology and only rarely with FTLD-tau or $\mathrm{AD}$ pathology. ${ }^{49} 5657$ PNFA is commonly associated with FTLD-tau, ${ }^{56} 5859$ although $\mathrm{AD}$ and, to a lesser extent, FTLDTDP pathology have also been described. ${ }^{49} 5758$ Finally, LPA is predominantly associated with $\mathrm{AD}$ pathology. ${ }^{58} 59$ Although these are relatively strong associations, they are not absolute, and it is currently not possible to predict with certainty the underlying pathology of specific PPA syndromes. ${ }^{57}$ However, using multimodal predictors including qualitative clinical features, neuropsychological test scores and atrophy on MRI improve the non-invasive prediction of the underlying pathology in non-fluent PPA (table 1). ${ }^{60}$

Motor neuron disease (MND) may occur early or late in the disease course in a subset of FTD patients. ${ }^{65}{ }^{66}$ Muscle atrophy, weakness and fasciculations are often most prominent in the upper extremities and the tongue. The disease has a rapidly progressive course with a mean survival of 3 years. It is now accepted that FTD and MND are part of the same clinicopathological spectrum. A third of all FTD-MND cases have a positive 
Table 1 Language characteristics in primary progressive aphasia variants ${ }^{52} 55$ 61-64

\begin{tabular}{|c|c|c|c|c|c|c|c|c|}
\hline & $\begin{array}{l}\text { Spontaneous } \\
\text { speech }\end{array}$ & $\begin{array}{l}\text { Motor } \\
\text { speech }\end{array}$ & $\begin{array}{l}\text { Single word } \\
\text { comprehension }\end{array}$ & $\begin{array}{l}\text { Grammar/sentence } \\
\text { comprehension }\end{array}$ & $\begin{array}{l}\text { Sentence } \\
\text { repetition }\end{array}$ & $\begin{array}{l}\text { Naming/word } \\
\text { retrieval }\end{array}$ & Fluency & Reading \\
\hline $\begin{array}{l}\text { Semantic } \\
\text { dementia }\end{array}$ & $\begin{array}{l}\text { Fluent } \\
\text { Grammatically } \\
\text { correct } \\
\text { Empty and } \\
\text { circumlocutory } \\
\text { Semantic errors }\end{array}$ & Spared & Impaired & $\begin{array}{l}\text { Initially spared, } \\
\text { becomes impaired as } \\
\text { single word comprehension } \\
\text { deteriorates }\end{array}$ & Spared & $\begin{array}{l}\text { Anomia } \\
\text { (nouns }>\text { verbs) }\end{array}$ & $\begin{array}{l}\text { Impaired } \\
\text { (categorical> } \\
\text { letter) }\end{array}$ & $\begin{array}{l}\text { Surface } \\
\text { dyslexia }\end{array}$ \\
\hline $\begin{array}{l}\text { Progressive } \\
\text { non-fluent } \\
\text { aphasia }\end{array}$ & $\begin{array}{l}\text { Decreased fluency } \\
\text { Articulatory errors } \\
\text { Apraxia of speech } \\
\text { and/or } \\
\text { Agrammatism }\end{array}$ & Impaired & $\begin{array}{l}\text { Initially } \\
\text { spared, } \\
\text { becomes affected } \\
\text { in late disease }\end{array}$ & $\begin{array}{l}\text { Impaired for complex } \\
\text { sentences }\end{array}$ & $\begin{array}{l}\text { Can be } \\
\text { impaired }\end{array}$ & $\begin{array}{l}\text { Spared initially } \\
\text { but anomic as } \\
\text { disease } \\
\text { progresses } \\
\text { (verbs }>\text { nouns) }\end{array}$ & $\begin{array}{l}\text { Impaired (letter> } \\
\text { categorical) }\end{array}$ & $\begin{array}{l}\text { Phonological } \\
\text { dyslexia }\end{array}$ \\
\hline $\begin{array}{l}\text { Logopenic or } \\
\text { phonological } \\
\text { variant }\end{array}$ & $\begin{array}{l}\text { Slow output with } \\
\text { word-finding pauses } \\
\text { Phonemic parapha- } \\
\text { sias }\end{array}$ & Spared & Relatively spared & $\begin{array}{l}\text { Impaired for simple } \\
\text { and complex sentences }\end{array}$ & Impaired & Impaired & $\begin{array}{l}\text { Impaired (letter } \approx \\
\text { categorical) }\end{array}$ & $\begin{array}{l}\text { Phonological } \\
\text { dyslexia }\end{array}$ \\
\hline
\end{tabular}

family history for dementia, FTD, MND or FTD-MND. The causative gene defect in FTD-MND has yet to be discovered.

Some patients with predominantly right temporal lobe atrophy (RTLA) present with prominent behavioural changes, episodic memory disturbances, topographical disorientation and prosopagnosia. ${ }^{67}{ }^{68}$ Patients with RTLA are usually diagnosed clinically with either bvFTD or SD. ${ }^{68}$ It has been suggested that patients with bvFTD and RTLA have FTLD-tau pathology, whereas patients with SD and RTLA have FTLD-TDP pathology. ${ }^{68}$

\section{NEUROPSYCHOLOGY AND SOCIAL COGNITION}

Impairment of executive function including planning, organisation, judgement, problem solving and mental flexibility is characteristic of FTD, ${ }^{69}$ whereas memory, visual perception and spatial skills are usually relatively well preserved. ${ }^{50} 70-74$ However, executive dysfunction may be absent or overshadowed by pronounced behavioural changes in early disease and may also be seen in $\mathrm{AD}{ }^{75}$ Verbal fluency (letter and categorical) is usually impaired in bvFTD and PNFA, but to a lesser degree also in $\mathrm{AD} .^{76-78}$ In $\mathrm{SD}$ patients, semantic fluency is more impaired than letter fluency. ${ }^{76} 78$

Early episodic memory impairment, a characteristic feature of $\mathrm{AD}$, has also been reported in pathologically proven bvFTD cases, and in patients with GRN gene mutations. ${ }^{79} 80$ Though orientation in time and place, delayed free recall and delayed recognition are more often impaired in $\mathrm{AD}$ than in $\mathrm{FTD}$ at initial assessment, it still remains difficult to differentiate FTD from $\mathrm{AD}$ in the early phase using standard neuropsychological tests. ${ }^{81}$

As standard neuropsychological tests cannot reliably differentiate bvFTD from $A D,{ }^{82-84}$ several investigators have explored the utility of emotional processing and social recognition tasks in the clinical diagnosis of FTD over recent years. Social dysfunction and emotional blunting commonly occur in FTD. 4475 85-91 Theory of Mind (ToM) tests require the interpretation of social situations and ascribing mental state to oneself and others, and may reveal subtle deficits not detected with standard neuropsychological testing. ${ }^{75}$ Recent reports suggest that the neural basis for ToM tasks, social cognition and empathy lies within the medio- and/or orbitofrontal cortex, which is affected early in bvFTD ${ }^{92}$ Patients with bvFTD have impaired scores on these tests of social judgements and cognitive flexibility, and express concrete, literal interpretations. ${ }^{75} 93$ Performances in ToM tests do not correlate with executive functioning on standard neuropsychological testing in the early phase. ${ }^{85} 9495$ However, in a more advanced stage, when atrophy spreads to dorsolateral frontal structures, the ToM ability and executive functioning become strongly related. ${ }^{75} 9394$ Empathy as rated by care givers is clearly impaired in bvFTD and SD patients, and correlates with ToM tasks. ${ }^{85} 96$

In line with these observations, recognition of facial emotions is impaired in patients with bvFTD, in particular for negative emotions (anger, fear, sadness and disgust) (figure 1D). ${ }^{85} 87-9197$ The same applies for the recognition of vocal emotions, in particular for anger and sad voices. ${ }^{89}$ Interpretation of sarcastic statements is impaired in FTD, and is correlated with the ability to recognise negative emotions. ${ }^{44}$ Self-conscious emotions, such as embarrassment and amusement, are another important aspect of emotion functioning which may be disrupted in FTD. ${ }^{98} 99$ Social cognition tests also seem to help to differentiate bvFTD patients with imaging abnormalities from the nonprogressive bvFTD with normal neuroimaging. ${ }^{85} 96$

It will be interesting to investigate further whether impaired social cognition is a very early feature of familial FTD as has already been described in a single case study of a presymptomatic mutation carrier; studying presymptomatic mutation carriers may allow identification of sensitive (even preclinical) cognitive predictors of decline and its neural substrate. ${ }^{100}$

\section{NEUROIMAGING}

Patients with FTD classically have frontal and temporal atrophy, and hypometabolism which is often asymmetrical. In the clinical setting this is often best seen using volumetric structural MRI scans (with coronal T1 images being particularly useful for assessing asymmetry) or with functional imaging using either FDG-PET or, less commonly, HMPAO-SPECT. More recently, however, neuroimaging studies have aimed to refine these initial findings, mostly in clinical cohorts, but also in pathologically and genetically confirmed FTD.

Studies of mild bvFTD in clinically defined cohorts show involvement particularly of frontal and paralimbic areas, ${ }^{101}$ namely the anterior cingulate cortex and frontal insula as well as medial frontal and orbitofrontal cortices, hippocampus, striatum and thalamus, more in the right than in the left hemisphere (figure 1A). With increasing disease severity, more diffuse atrophy in similar areas is seen with involvement of more lateral frontal areas and subsequently more posterior temporal and anterior parietal atrophy. ${ }^{102}$ It remains unclear whether this pattern of atrophy is a feature of bvFTD independent of the underlying pathology (which is heterogeneous) or whether different pathologies have distinct patterns of atrophy. Unfortunately, there are currently no studies which directly compare all of the pathological subtypes. Patients with FUS pathology seem to have a similar pattern of frontal paralimbic atrophy to 
that described above but in addition have severe caudate involvement compared with FTLD-tau or FTLD-TDP. ${ }^{103-105}$ Studies comparing genetically defined FTD patients with either GRN or microtubule associated protein tau (MAPT) mutations 106107 have described different patterns between the two groups: GRN mutations are associated with asymmetrical frontal, temporal and inferior parietal lobe atrophy, whereas MAPT mutations are associated with relatively symmetrical anteromedial temporal lobe and orbitofrontal grey matter atrophy. ${ }^{106} 107$ The presence of early parietal lobe atrophy in GRN mutations, a feature which may distinguish such cases from other FTD patients, has been shown in studies of presymptomatic mutation carriers. ${ }^{100} 108$ Whether patients with different mutations in the same gene have distinct patterns of atrophy is unclear, although one small study suggests there may be a difference between patients with $M A P T$ mutations that affect splicing of exon 10 (more medial temporal lobe atrophy) compared with mutations that do not affect splicing of exon 10 (more lateral temporal lobe atrophy). ${ }^{109}$ Bringing these findings together, one study that used a cluster analysis to investigate bvFTD suggested there may be four types of bvFTD anatomically: a temporal-dominant subtype associated with MAPT mutations; a temporofrontoparietal subtype that can be associated with GRN mutations but also with other pathologies such as corticobasal degeneration (CBD); as well as frontal-dominant and frontotemporal subtypes. ${ }^{110}$ Larger studies of pathologically proven patients are needed to confirm these findings.

Early voxel-based morphometry (VBM) studies of SD showed asymmetrical atrophy of the anterior and inferior temporal lobes, ${ }^{111} 112$ usually affecting the left more than the right hemisphere (figure 1B). These findings were supported by subsequent region-of-interest (ROI) studies of the temporal lobe, which identified involvement particularly of the temporal pole and anterior parts of the entorhinal cortex, fusiform gyrus, inferior temporal gyrus, amygdala and hippocampus with relative sparing of the superior temporal gyrus. ${ }^{113} 114$ Most studies have used clinically defined cohorts, but one study looking at measurement of cortical thickness in patients with left greater than right temporal lobe atrophy showed a similar pattern of involvement in a pathologically confirmed cohort of patients, all with FTLD-TDP. ${ }^{115}$ This study also showed that areas within the left hemisphere outside the temporal lobe are involved with increasing disease severity, namely orbitofrontal, inferior frontal, insular and anterior cingulate cortices. ${ }^{115}$ Increasing involvement of the temporal lobe in the right hemisphere is seen with disease progression. ${ }^{115} 116$ A mirror-image pattern of initial atrophy and disease progression seems to occur in those with right greater than left temporal lobe involvement (RTLA). ${ }^{117}$ Although SD is characteristically FTLD-TDP pathologically, in a small number of cases, Pick's disease (FTLD-tau) and occasionally $\mathrm{AD}$ pathology can be seen. One small study showed similar patterns of atrophy in the FTLD-TDP and FTLD-tau but with a qualitatively different pattern in those with $\mathrm{AD}$ who had mostly hippocampal involvement, lack of the knife-edge anterior temporal atrophy seen in the other groups and without the sparing of the superior temporal gyrus. ${ }^{118}$

Studies of PNFA are fewer and more heterogeneous, which reflects the clinical heterogeneity of this group. As with SD, there is asymmetrical involvement with more atrophy in the left hemisphere and most significant involvement of the inferior frontal lobe and anterior insula (figure 1C). ${ }^{52} 116119120$ With increasing severity, there is involvement of left superior temporal, middle and superior frontal and anterior parietal lobes. ${ }^{116}$ ROI studies have also shown involvement of the caudate in PNFA. ${ }^{121}$ There are few pathologically confirmed studies of PNFA, and these are usually in mixed pathological groups, but they show similar findings to the clinical cohort studies. ${ }^{116} 122$ Some small studies suggest there may be different patterns of atrophy in PNFA patients with PSP clinically (and therefore likely pathologically) compared with those without PSP, ${ }^{123}$ and also in those with GRN mutations (FTLD-TDP pathologically) compared with those without. ${ }^{63}$ More detailed studies of PNFA subgroups will be needed to confirm these findings (figure 1).

Being able to distinguish FTD from AD is important clinically, and recent studies have suggested that atrophy or cortical thinning of precuneus, posterior cingulate, posterior temporal and parietal areas is characteristic of $\mathrm{AD}$ pathology independent of clinical diagnosis and is therefore helpful in distinguishing those with atypical $\mathrm{AD}$ presentations (which may include bvFTD or a progressive aphasia) from those with FTLD pathology. ${ }^{124-126}$ Clinically, however, VBM or cortical thickness studies are unlikely to be available, and simpler techniques such as visual rating scales have been developed which can help to differentiate FTD from $\mathrm{AD}{ }^{127}$ More sophisticated methods using techniques such as support vector machines are being developed which allow automatic classification of patients into FTD or AD groups with little user input necessary, although currently these are computationally demanding. ${ }^{128}$ Another possibility is to use support vector machine-based MRI analyses that integrate grey matter and diffuse tensor imaging (DTI),
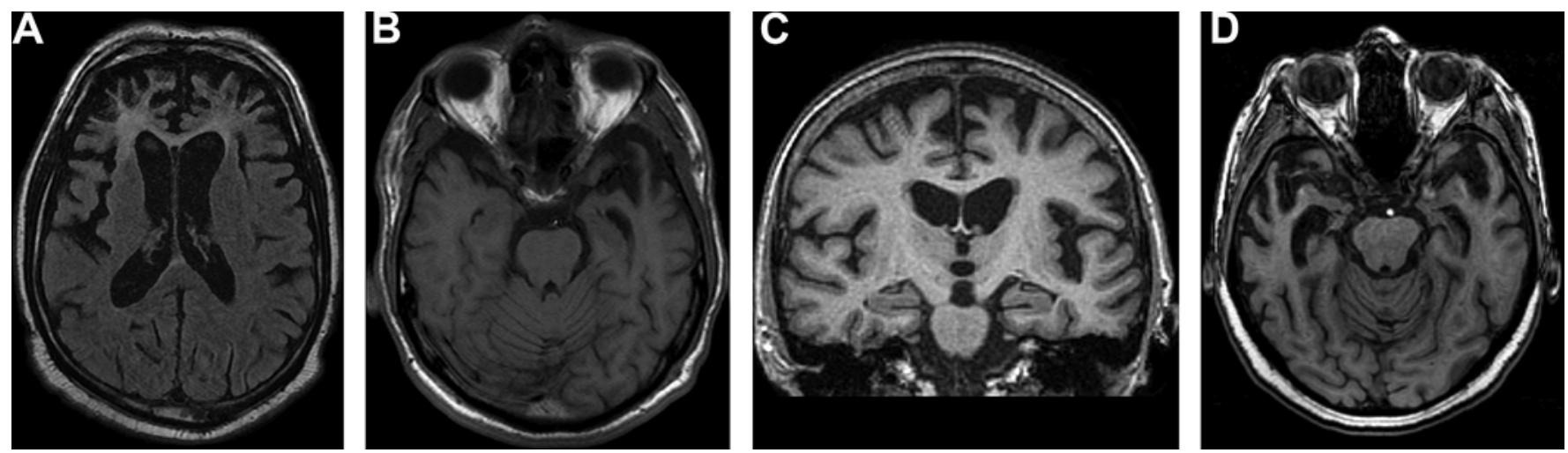

Figure 1 Imaging of frontotemporal dementia (FTD) subtypes. (A) Frontal atrophy on axial fluid attenuated inversion recovery MRI of a patient with behavioural variant of FTD (bvFTD). (B) Axial T1-weighted image with left temporal lobe atrophy in a patient with semantic dementia (SD). (C) Coronal T1-weighted MR image of a patient with progressive non-fluent aphasia (PNFA) and left inferior frontal and superior temporal atrophy. (D) Axial T1weighted MR image in a patient with predominant right temporal lobe atrophy. 
which has shown accurate pathological or CSF-defined categorisation of FTLD and AD. ${ }^{129}$

A different neuroimaging tool that accurately differentiates FTLD from $\mathrm{AD}$ is arterial spin labelling (ASL) perfusion MRI, which reveals non-invasive quantification of cerebral blood flow, without the use of ionising radiation as in SPECT or PET. ${ }^{130}$ Patients with $\mathrm{AD}$ pathologically can also be defined using amyloid molecular imaging (eg, PIB-PET) ${ }^{131}$ but the availability of such scans is currently limited to a few large research centres.

One of the more novel concepts to emerge from recent neuroimaging studies of FTD using the technique of restingstate FMRI is the idea that FTD is caused by degeneration within specific intrinsic functional connectivity networks that are selectively vulnerable to FTLD pathologies. ${ }^{132}$ Consistent with earlier VBM findings in structural MRI studies of bvFTD, resting-state FMRI studies show attenuated connectivity within an anterior 'salience' network of dorsal anterior cingulate and frontoinsular cortices which has connectivity to subcortical and limbic structures. ${ }^{133}$ In contrast, there appears to be enhanced connectivity in the more posterior 'default' network which has been shown to be affected in $\mathrm{AD} .^{133}$ These findings have been linked to specific neuropathological findings (early involvement of von Economo neurons in FTD), ${ }^{134}$ and further work will be needed to look at whether specific pathological subtypes can be linked to specific and distinct neural network degeneration.

\section{CEREBROSPINAL FLUID AND PLASMA BIOMARKERS}

Currently cerebrospinal fluid (CSF) biomarkers have limited ability to identify FTD reliably. This might be explained by both the pathological heterogeneity and the large variation in neurodegenerative severity. Levels of CSF tau in FTD are normal, increased or even decreased. ${ }^{135}$ Levels of CSF phosphorylated tau are essentially normal in FTD, in contrast with $\mathrm{AD}$. Levels of CSF amyloid $\beta^{1-42}$ have been found to be either decreased or in the normal range. An indication of lower amyloid $\beta^{1-40}$ levels in FTD compared with $\mathrm{AD}$ and control subjects, might be particularly useful to distinguish FTD patients from subjects without a neurodegenerative disorder. ${ }^{135}$

Decreased levels of progranulin protein are found in plasma, serum and cerebrospinal fluid (CSF) by ELISA, and may reliably differentiate GRN mutations carriers from non-carriers. ${ }^{136-140}$

It remains to be investigated if measurement of plasma or CSF levels of TDP-43 is useful diagnostically, as plasma phosphorylated TDP-43 levels have been found to be correlated with the extent of TDP-43 pathology in FTLD. ${ }^{141} 142$

Recent biomarker studies on CSF are using multianalyte profiling to derive novel biomarkers for neurodegenerative disorders and have delivered some promising neuropeptides (agouti-related peptide (AgRP), adrenocortotrophic hormone (ACTH), IL-17 and IL-23 and Fas) which are useful in distinguishing FTLD-TDP from FTLD-tau patients. ${ }^{143} 144$

\section{GENETICS}

A positive family history has been found in $30-50 \%$ of patients with bvFTD, whereas patients with SD or PNFA have a much lower frequency. $^{9-11} 21145146$ The heritability in FTD-MND differs between studies from 10 to $60 \% .^{9} 11146$ An autosomal dominant mode of inheritance is found in $10-27 \%$ of all FTD patients. $^{9-11} 21145146$

Genetic heterogeneity of FTLD is reflected by the identification of mutations in the MAPT and progranulin (GRN) genes in approximately $50 \%$ of the familial cases, whereas mutations in the valosin containing protein $(V C P)$, charged multivesicular body protein $2 B(C H M P 2 B), T A R-D N A$ binding protein $(T A R D P)$ and fused in sarcoma (FUS) genes are found in less than 5\%. Familial FTD-MND has been linked to chromosome 9, but the causative gene defect has yet to be discovered.

\section{Microtubule associated protein tau (MAPT)}

More than 40 mutations in the MAPT gene have been identified in families with FTD and parkinsonism linked to chromosome 17q (FTDP-17) with accumulation of hyperphosphorylated tau protein in neurons and/or glial cells (http://www.molgen.ua.ac. be/FTDmutations). ${ }^{12}$ Alternative splicing of exons 2,3 and 10 of the MAPT gene gives rise to six isoforms: three isoforms containing three amino-acid repeats (3R), and three isoforms with four repeats (4R). ${ }^{147}$ Mutations can be distinguished into missense mutations in exon 9-13 affecting the normal function of the tau protein to stabilise microtubules, and intronic and some coding mutations affecting the splicing of exon 10 at the mRNA level, resulting in a change in ratio of $3 \mathrm{R}$ to $4 \mathrm{R}$ tau isoforms. ${ }^{148}$

The mean age at onset is 55 years and usually shows a small intrafamilial variation between 45 and 65 years, although the disease may present before the age of 40 years or after 70 years in a few mutations. ${ }^{149}$ The mean duration of illness is approximately 9 years, but varies between 5 and 20 years. There exists a dementia-dominant phenotype with prominent behavioural changes including disinhibition and obsessive-compulsive behaviour $^{149}$ and a parkinsonism-dominant phenotype with CBS or PSPlike syndromes. ${ }^{80}$ Patients may develop language problems-for example, mild semantic impairment during the illness. ${ }^{150}$

\section{Progranulin}

More than 60 mutations in the GRN gene on chromosome 17 (1.7 $\mathrm{Mb}$ centromeric to the MAPT gene) have been identified to date, and account for approximately $5-10 \%$ of all FTD patients, and up to $22 \%$ in familial FTD. ${ }^{9} 1314151-153$ Its frequency is similar to that of MAPT gene mutations in hereditary FTD. ${ }^{9} 146$ $G R N$ gene mutations are occasionally reported in sporadic cases. ${ }^{9} 151-153$ Whether this is due to a low penetrance of the GRN mutation in one of the parents or to a spontaneous mutation in the patient is unknown.

$G R N$ encodes the progranulin protein, which is a growth factor implicated in wound healing and tumour growth inflammation, and is abundantly expressed in specific neuronal subsets. ${ }^{154}$ The neuropathology of patients with GRN mutations is characterised by tau-negative, and ubiquitin- and TDP43-positive inclusions. ${ }^{155}$

The mean age at onset is around 60 years, ranging from 35 to 89 years, with a penetrance of $90 \%$ by the age of 70 years. ${ }^{80} 151$ Within families, the onset age shows considerable variation with a difference of up to 20 years between consecutive generations. ${ }^{980}$ The mean duration is 8 years (range 3-22 years).

Apathy and social withdrawal are the most common behavioural changes. Twenty-five per cent of patients present with early isolated language dysfunction, suggestive of an anomic non-fluent type (without motor speech impairment) and with relatively early single word comprehension impairment. ${ }^{156}$ Hallucinations and delusions are frequently reported. ${ }^{157-159}$ Episodic memory deficits occur in $10-30 \%$, and may lead to the clinical diagnosis of amnestic variant of MCI or together with parietal deficits, such as dyscalculia, visuospatial dysfunction and limb apraxia to $\mathrm{AD} .^{157} 158$ 160-162

Extrapyramidal features are frequently seen and include CBS with limb apraxia, asymmetrical parkinsonism and dystonia. ${ }^{157} 158163-165$ ALS is only a very rare part of the clinical spectrum within GRN families 9151161163166 _for example, it has been reported in a single patient of a large Canadian family. ${ }^{13} 167$ 


\section{Other hereditary forms}

The genetic heterogeneity of FTD is further emphasised by the rare occurrence of mutations in the VCP, CHMP2B, TARDP and FUS genes. ${ }^{168-171}$ VCP gene mutations are associated with inclusion body myopathy (90\%), Paget's disease of the bone (45\%) and FTD (38\%) (IBMPFD), presenting between the age of 40 and 60 years. ${ }^{168} 172$

The clinical presentation of $C H M P 2 B$ gene mutations consists of a frontal lobe syndrome and a more global cognitive impairment, with parkinsonism, dystonia, pyramidal signs and myoclonus later in the course of the disease. ${ }^{173}$ ALS has been reported in only two patients. ${ }^{174}$

TARDBP gene mutations on chromosome 1 are found in $5 \%$ of familial ALS, ${ }^{170} 175-182$ and occasionally in FTD or FTD-MND cases. ${ }^{170} 171$ Also, FUS gene mutations are found in $5 \%$ of the familial ALS cases, ${ }^{183-186}$ and in one clinical bvFTD patient, but not in FTD-MND. ${ }^{187}$ However, for the majority of the FTDMND families, the genetic defect has yet to be identified. A number of these families have been linked to a locus on chromosome 9p13.2-21.3, but at time of writing an exhaustive sequencing of all genes in this region has not revealed any coding or splice-donor site mutations. ${ }^{188-193}$

There still remains a subgroup of FTD patients with a positive family history without known gene mutations. These patients usually have bvFTD and memory problems with or without MND, TDP-43 pathology and neuronal loss and gliosis of the cornu ammonis 1 and subiculum of the hippocampus (hippocampal sclerosis) at neuropathological examination. ${ }^{9}$

\section{Genetic risk factors}

Several investigators have tried to identify genetic risk factors for FTD. Homozygosity for the Tallele of the SNP rs5848 was found to have a 3.2-fold increased risk for developing FTLD-TDP, ${ }^{194}$ but this observation could not be replicated in other studies. ${ }^{195}{ }^{196}$ The same is true for three other SNPs of the GRN gene, which were initially found to be associated with younger onset age or shorter survival in FTLD or ALS. ${ }^{9194}$ Also, an association of the Cystatin C gene (CST3) haplotype B, the $\varepsilon 4$ allele of the apolipoprotein E gene $(A P O E)$, and heterozygosity of the codon 129 polymorphism of the prion protein gene (PNRP) could not be confirmed in further studies. ${ }^{197-201}$ Finally, SNPs in the Ubiquitin associated protein 1 (UBAP1) gene have been associated with FTD, ${ }^{202}$ which was supported by a reduced mRNA expression from the diseaseassociated haplotype in a quantitative analysis. ${ }^{202}$

Recently, an international genome-wide association study (GWAS) with pathologically proven FTLD-TDP patients has demonstrated a significant association with three SNPs within the TMEM106B gene on chromosome 7p21. ${ }^{203}$ TMEM106B variants also contribute to genetic risk for FTLD-TDP in individuals with GRN gene mutations. ${ }^{203}$ TMEM106B encodes an uncharacterised transmembrane protein of 274 amino acids. ${ }^{203}$ Expression data showed increased TMEM106B expression in the frontal cortex of FTLD-TDP than in controls, suggesting that increased TMEM106B expression in the brain might be linked to mechanisms of disease in FTLD-TDP and that risk alleles at TMEM106B confer genetic susceptibility by increasing gene expression. ${ }^{203}$

\section{Genetic screening in clinical practice}

The benefit of genetic screening in FTD depends on the strength of the family history and the clinical subtype. Genetic defects, either MAPT or GRN, are most often found in patients with an autosomal dominant form of bvFTD. ${ }^{9} 146$ Genetic screening in $\mathrm{SD}$ is unlikely to be useful, although patients who develop semantic impairment later in the illness may have a MAPT gene mutation, ${ }^{9} 146$ whereas a GRN mutation can be found in a familial form of PNFA. ${ }^{9} 146156$ Current gene defects are very rare in FTD-MND, and genetic screening is therefore likely not to be useful at present. ${ }^{146}$ Screening in sporadic patients will be of little value, as a very few mutations have been found in sporadic patients, except for those with a concealed or incomplete family history. In this latter group, careful consideration is necessary before embarking on genetic screening. ${ }^{146}$

\section{Pathology}

FTLD is the common underlying pathology of clinical FTD subtypes, and also includes ALS, PSP and CBD. The major pathological hallmark of FTLD is selective atrophy of the frontal and temporal cortex, with neuronal loss, gliosis and spongiosis of the superficial layers, especially of layer II. The nomenclature has been changed several times since it was first described by Arnold Pick over a 100 years ago. ${ }^{6}$ The term Pick's disease is now reserved for cases of FTLD with intraneuronal argyrophilic inclusions, the so-called Pick bodies, which consist of abnormal three-repeat tau protein (FTLD-tau)

FTLD is a neuropathologically heterogeneous disorder, which can be divided into two major subtypes; FTLD with tau-positive inclusions (FTLD-tau), and FTLD with ubiquitin-positive and TDP-43-positive, but tau-negative inclusions (FTLDTDP). ${ }^{18}$ FTLD-tau includes patients with MAPT mutations, Pick's disease, PSP, CBD, argyrophilic grain disease (AGD) and multiple system tauopathy with dementia (MSTD). ${ }^{18}$ MAPT mutations are associated with different types of tau inclusions (Pick bodies, neurofibrillar tangles and pretangles) in the frontal and temporal cortex, hippocampus and subcortical nuclei, and sometimes in midbrain, brainstem, cerebellum and spinal cord. ${ }^{149}$ Glial tangles and coiled bodies in white matter are found in a few $M A P T$ mutations and consist predominantly of four-repeat tau isoforms. ${ }^{149}$

FTLD-TDP is the second major subtype of FTLD, with ubiquitin-positive inclusions, which have the TDP-43 protein as major constituent. ${ }^{204}$ The further classification into four different FTLDTDP subtypes according to the morphology and distribution of the inclusions ${ }^{1516}$ can be predicted to some extent by the clinical picture: SD is strongly associated with abundant dystrophic neurites (type 1), FTD-MND with numerous neuronal cytoplasmatic inclusions in both superficial and deep cortical laminae (type 2), GRN mutations are characterised by numerous cytoplasmatic inclusions, dystrophic neurites and neuronal intranuclear inclusions (type 3), and VCP mutations are characterised by numerous intranuclear and infrequent number of neuronal cytoplasmatic inclusions and dystrophic neurites (type 4). ${ }^{15} 17$ It remains unclear what differences in underlying pathophysiology determine the distinction between these TDP-43 subtypes.

A small number of FTLD cases with ubiquitin-positive, TDP-43 negative pathology, ${ }^{205-208}$ have recently shown immunoreactivity with the FUS antibody. ${ }^{19} 103$ None of these FTLDFUS cases had FUS gene mutations. ${ }^{208}$ FTLD-FUS cases are characterised by a young age at onset, bvFTD, negative family history and caudate atrophy on MRI. ${ }^{103} 104$ FUS-positive inclusions are also found in patients with neuronal filament inclusion disease (NIFID). ${ }^{209}$ NIFID patients mostly present with bvFTD symptoms, a negative family history and pyramidal and/or extrapyramidal movement disorder. ${ }^{209}$

The FUS protein contains 526 amino acids and is as a nuclear protein involved in DNA repair and the regulation of RNA splicing. ${ }^{183} 184$ Mutations in the FUS gene on chromosome 16 have emphasised its pathogenetic role in the clinicopathological spectrum of FTD and ALS. ${ }^{187}$ 
Finally, the pathological heterogeneity of FTLD has been further emphasised by cases with ubiquitin-positive, TDP-43 and FUS-negative inclusions, termed FTLD-UPS. Most of the FTLD-UPS cases carry a $C H M P 2 B$ mutation, ${ }^{210}$ but there remain a few without $C H M P 2 B$ mutations. ${ }^{208}$ Further research on FTLD-UPS is necessary to elucidate the full complement of FTLD pathologies. ${ }^{208}$

Future clinicopathological studies, including neuroimaging and genetics, are necessary to improve the prediction of the underlying pathology. In particular, the prediction of the underlying pathology in (sporadic) bvFTD will be important, as tau-, TDP-43- or FUS pathology could be the disease-modifying protein in these patients (figure 2).

\section{FUTURE DIRECTIONS}

Important advances in the field research on FTD over the last decade have led to an impressive change in the clinical recognition of this disease. Future scientific efforts should focus on three major lines of research: (1) to improve the early detection of the disease; (2) to develop reliable markers in predicting the underlying pathology; and (3) to unravel its pathophysiology in order to develop therapeutic strategies preventing or delaying the disease process.

Concerning the clinical diagnosis, an international study has been initiated to revise the clinical criteria based on a large sample of pathologically proven cases. The aim is that neuroimaging and genetic data, and the most salient clinical features should be incorporated in a revised set of simplified criteria of bvFTD. A second clinical issue will be to monitor the progression of the disease in individual patients, which has now become available by the recent introduction of FTD rating scale (FRS) ${ }^{211}$ characterising the features of different severity stages. Finally, the use of social cognition tasks will help in the early detection of bvFTD and discrimination from non-progressive bvFTD. Their use offers us the opportunity to investigate the relative contributions of individual brain regions to social cognition in FTD.

Although relatively specific atrophy patterns have been found in clinical FTD subtypes, neuroimaging features as biomarkers for underlying pathology in bvFTD have yet to be determined. Support vector machines and arterial spin labelling are new neuroimaging tools to accurately differentiate FTD from $\mathrm{AD}$. Another novel and promising neuroimaging technique is resting-

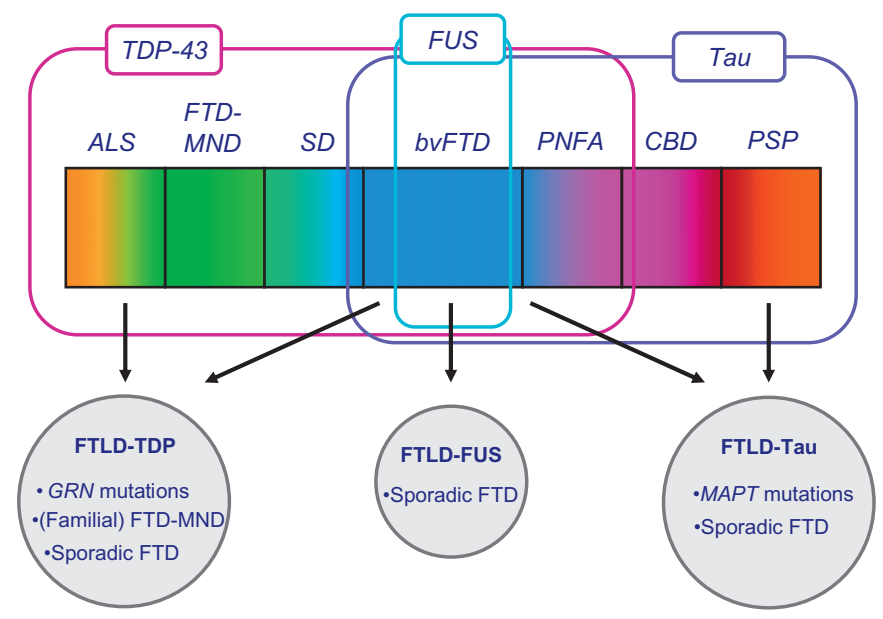

Figure 2 Clinical, genetic and pathological spectrum of frontotemporal lobar degeneration. state fMRI, which has shown changes in the salience network in FTD. An interesting question will be whether the early (or even presymptomatic) MAPT or GRN mutation carriers can be detected using this technique.

The differentiation of PPA into SD, PNFA and LPA has proven to be an important step in predicting underlying pathology in these groups: TDP-43 pathology is most commonly found in SD, tau-pathology in PNFA and AD pathology in LPA. Multimodal predictors, including clinical parameters, neuropsychological test scores and atrophy patterns, will improve the prediction of the underlying pathology in clinical PPA syndromes. However, radioactive compounds to detect tau or TDP-43 pathology in the brain with PET scanning would be of great help to differentiate bvFTD into its two major pathological subtypes during life. The recent recognition of the FUS protein as a pathological component of neuronal inclusions in a specific subtype of FTLD emphasises the existence of different pathways and will also contribute to further understanding of the underlying pathophysiology. Another strategy would be the development of new CSF biomarkers, which could be derived by large-scale proteomics analysis.

Several common (MAPT, GRN) and rare (VCP, CHMP2B, $T A R D B P, F U S$ ) genetic factors have been found in hereditary FTD over recent years. However, we still have to identify one or more gene defects in familial FTD with and without MND. Whole exome sequencing as innovative genetic technique might reveal new genetic defects in small families with FTD and for pathologically well-characterised FTLD subtypes (such as FTLDFUS). Identification of novel genetic defect(s) will help to understand the pathophysiology of TDP-43 in hereditary and probably also of the sporadic FTLD-TDP. A large genome-wide association study of more than 3000 DNA samples is currently under way and may hopefully reveal additional genetic factors with a small effect on the disease process.

All these small steps in unravelling the pathophysiology should finally lead to the development of therapeutic interventions for FTD.

Funding HS and JCvS are funded by Stichting Dioraphte and Hersenstichting. The Dementia Research Centre is an Alzheimer's Research Trust Co-ordinating centre and receives support from the NIHR Biomedical Research Centres scheme. NCF is funded by the Medical Research Council and is an NIHR Senior Investigator.

\section{Competing interests None.}

Provenance and peer review Not commissioned; externally peer reviewed.

\section{REFERENCES}

1. Anon. Clinical and neuropathological criteria for frontotemporal dementia. The Lund and Manchester Groups. J Neurol Neurosurg Psychiatry 1994:57:416-18.

2. Neary D, Snowden JS, Gustafson L, et al. Frontotemporal lobar degeneration: a consensus on clinical diagnostic criteria. Neurology 1998;51:1546-54.

3. McKhann GM, Albert MS, Grossman M, et al. Clinical and pathological diagnosis of frontotemporal dementia: report of the Work Group on Frontotemporal Dementia and Pick's Disease. Arch Neurol 2001;58:1803-9.

4. Ratnavalli E, Brayne C, Dawson K, et al. The prevalence of frontotemporal dementia. Neurology 2002;58:1615-21.

5. Harvey RJ, Skelton-Robinson M, Rossor MN. The prevalence and causes of dementia in people under the age of 65 years. J Neurol Neurosurg Psychiatry 2003;74:1206-9.

6. Pick A. Über die Beziehungen der senilen Hirnatropie zur Aphasie. Pragen Medizinischen Wochenschrift 1892;17:165-7.

7. Alzheimer A. Über eigenartige Krankheitsfälle des späteren Alters. Zbl Ges Neurol Psych 1911:4:356-85.

8. Kertesz A, McMonagle P, Blair M, et al. The evolution and pathology of frontotemporal dementia. Brain 2005;128:1996-2005.

9. Seelaar H, Kamphorst W, Rosso SM, et al. Distinct genetic forms of frontotemporal dementia. Neurology 2008;71:1220-6.

10. Chow TW, Miller BL, Hayashi VN, et al. Inheritance of frontotemporal dementia. Arch Neurol 1999:56:817-22. 
11. Goldman JS, Farmer JM, Wood EM, et al. Comparison of family histories in FTLD subtypes and related tauopathies. Neurology 2005;65:1817-19.

12. Hutton M, Lendon CL, Rizzu P, et al. Association of missense and $5^{\prime}$-splice-site mutations in tau with the inherited dementia FTDP-17. Nature 1998;393 $702-5$.

13. Baker M, Mackenzie IR, Pickering-Brown SM, et al. Mutations in progranulin cause tau-negative frontotemporal dementia linked to chromosome 17. Nature 2006; 442:916-19.

14. Cruts M, Gijselinck I, van der Zee J, et al. Null mutations in progranulin cause ubiquitin-positive frontotemporal dementia linked to chromosome 17q21. Nature 2006; 442:920-4.

15. Sampathu DM, Neumann M, Kwong LK, et al. Pathological heterogeneity of frontotemporal lobar degeneration with ubiquitin-positive inclusions delineated by ubiquitin immunohistochemistry and novel monoclonal antibodies. Am J Pathol 2006:169:1343-52

16. Mackenzie IR, Baborie A, Pickering-Brown S, et al. Heterogeneity of ubiquitin pathology in frontotemporal lobar degeneration: classification and relation to clinical phenotype. Acta Neuropathol (Berl) 2006;112:539-49.

17. Cairns NJ, Bigio EH, Mackenzie IR, et al. Neuropathologic diagnostic and nosologic criteria for frontotemporal lobar degeneration: consensus of the Consortium for Frontotemporal Lobar Degeneration. Acta Neuropathol (Berl) 2007:114:5-22.

18. Mackenzie IR, Neumann M, Bigio EH, et al. Nomenclature and nosology for neuropathologic subtypes of frontotemporal lobar degeneration: an update. Acta Neuropathol 2010;119:1-4.

19. Neumann M, Rademakers R, Roeber $\mathbf{S}$, et al. A new subtype of frontotemporal lobar degeneration with FUS pathology. Brain 2009;132:2922-31.

20. Borroni B, Alberici A, Grassi M, et al. Is frontotemporal lobar degeneration a rare disorder? Evidence from a preliminary study in Brescia County, Italy. J Alzheimers Dis 2010;19:11-6.

21. Rosso SM, Donker Kaat L, Baks $\mathrm{T}$, et al. Frontotemporal dementia in The Netherlands: patient characteristics and prevalence estimates from a populationbased study. Brain 2003;126:2016-22.

22. Brun A. Frontal lobe degeneration of non-Alzheimer type. I. Neuropathology. Arch Gerontol Geriatr 1987;6:193-208.

23. Ikeda M, Ishikawa T, Tanabe H. Epidemiology of frontotemporal lobar degeneration. Dementia Geriatr Cogn Disord 2004;17:265-8.

24. Gislason TB, Sjögren M, Larsson $L$, et al. The prevalence of frontal variant frontotemporal dementia and the frontal lobe syndrome in a population based sample of 85 year olds. J Neurol Neurosurg Psychiatry 2003;74:867-71.

25. Knopman DS, Petersen RC, Edland SD, et al. The incidence of frontotemporal lobar degeneration in Rochester, Minnesota, 1990 through 1994. Neurology 2004; 62:506-8.

26. Mercy L, Hodges JR, Dawson K, et al. Incidence of early-onset dementias in Cambridgeshire, United Kingdom. Neurology 2008;71:1496-9.

27. Hou CE, Yaffe K, Perez-Stable EJ, et al. Frequency of dementia etiologies in four ethnic groups. Dementia Geriatr Cogn Disord 2006;22:42-7.

28. Hodges JR, Davies $\mathrm{R}$, Xuereb J, et al. Survival in frontotemporal dementia. Neurology 2003:61:349-54.

29. Johnson JK, Diehl J, Mendez MF, et al. Frontotemporal lobar degeneration: demographic characteristics of 353 patients. Arch Neurol 2005;62:925-30.

30. Le Ber I, Guedj E, Gabelle A, et al. Demographic, neurological and behavioural characteristics and brain perfusion SPECT in frontal variant of frontotemporal dementia. Brain 2006;129:3051-65.

31. Bathgate D, Snowden JS, Varma A, et al. Behaviour in frontotemporal dementia, Alzheimer's disease and vascular dementia. Acta Neurol Scand 2001:103:367-78

32. Snowden JS, Bathgate D, Varma A, et al. Distinct behavioural profiles in frontotemporal dementia and semantic dementia. J Neurol Neurosurg Psychiatry 2001; 70:323-32

33. Snowden JS, Neary D, Mann DMA. Fronto-Temporal Lobar Degeneration: FrontoTemporal Dementia, Progressive Aphasia, Semantic Dementia. London: ChurchillLivingstone, 1996

34. Zamboni G, Huey ED, Krueger F, et al. Apathy and disinhibition in frontotemporal dementia: Insights into their neural correlates. Neurology 2008;71:736-42.

35. McMurtray AM, Chen AK, Shapira JS, et al. Variations in regional SPECT hypoperfusion and clinical features in frontotemporal dementia. Neurology 2006;66:517-22

36. Peters F, Perani D, Herholz K, et al. Orbitofrontal dysfunction related to both apathy and disinhibition in frontotemporal dementia. Dementia Geriatric Cogn Disord 2006;21:373-9.

37. Woolley JD, Gorno-Tempini ML, Seeley WW, et al. Binge eating is associated with right orbitofrontal-insular-striatal atrophy in frontotemporal dementia. Neurology 2007;69:1424-33.

38. Huey ED, Goveia EN, Paviol S, et al. Executive dysfunction in frontotemporal dementia and corticobasal syndrome. Neurology 2009;72:453-9.

39. Bozeat S, Gregory CA, Ralph MA, et al. Which neuropsychiatric and behavioural features distinguish frontal and temporal variants of frontotemporal dementia from Alzheimer's disease? J Neurol Neurosurg Psychiatry 2000;69:178-86.

40. Miller BL, lkonte C, Ponton $\mathrm{M}$, et al. A study of the Lund-Manchester research criteria for frontotemporal dementia: clinical and single-photon emission CT correlations. Neurology 1997:48:937-42.
41. Marra C, Quaranta D, Zinno M, et al. Clusters of cognitive and behavioral disorders clearly distinguish primary progressive aphasia from frontal lobe dementia, and Alzheimer's disease. Dementia Geriatr Cogn Disord 2007:24:317-26.

42. Chow TW, Binns MA, Cummings JL, et al. Apathy symptom profile and behavioral associations in frontotemporal dementia vs dementia of Alzheimer type. Arch Neurol 2009;66:888-93.

43. Davies RR, Kipps CM, Mitchell J, et al. Progression in frontotemporal dementia: identifying a benign behavioral variant by magnetic resonance imaging. Arch Neurol 2006; 63:1627-31

44. Kipps CM, Nestor PJ, Acosta-Cabronero J, et al. Understanding social dysfunction in the behavioural variant of frontotemporal dementia: the role of emotion and sarcasm processing. Brain 2009;132:592-603.

45. Kipps CM, Nestor PJ, Fryer TD, et al. Behavioural variant frontotemporal dementia: not all it seems? Neurocase 2007:13:237-47.

46. Rosen HJ, Hartikainen KM, Jagust W, et al. Utility of clinical criteria in differentiating frontotemporal lobar degeneration (FTLD) from AD. Neurology 2002;58:1608-15.

47. Knopman DS, Boeve BF, Parisi JE, et al. Antemortem diagnosis of frontotemporal lobar degeneration. Ann Neurol 2005:57:480-8.

48. Forman MS, Farmer J, Johnson JK, et al. Frontotemporal dementia: clinicopathological correlations. Ann Neurol 2006;59:952-62.

49. Alladi S, Xuereb J, Bak T, et al. Focal cortical presentations of Alzheimer's disease Brain 2007; 130:2636-45

50. Mendez MF, Shapira JS, McMurtray A, et al. Accuracy of the clinical evaluation for frontotemporal dementia. Arch Neurol 2007;64:830-5.

51. Rascovsky K, Hodges JR, Kipps CM, et al. Diagnostic criteria for the behavioral variant of frontotemporal dementia (bvFTD): current limitations and future directions. Alzheimer Dis Assoc Disord 2007;21:S14-18

52. Gorno-Tempini ML, Dronkers NF, Rankin KP, et al. Cognition and anatomy in three variants of primary progressive aphasia. Ann Neurol 2004:55:335-46.

53. Rosen HJ, Allison SC, Ogar JM, et al. Behavioral features in semantic dementia vs other forms of progressive aphasias. Neurology 2006;67:1752-6.

54. Gorno-Tempini ML, Brambati SM, Ginex V, et al. The logopenic/phonological variant of primary progressive aphasia. Neurology 2008;11:1227-34.

55. Rohrer JD, Crutch SJ, Warrington EK, et al. Progranulin-associated primary progressive aphasia: a distinct phenotype? Neuropsychologia 2010;48:288-97.

56. Davies RR, Hodges JR, Kril JJ, et al. The pathological basis of semantic dementia. Brain 2005:128:1984-95.

57. Grossman M. Primary progressive aphasia: clinicopathological correlations. Nat Rev Neurol 2010;6:88-97.

58. Mesulam M, Wicklund A, Johnson N, et al. Alzheimer and frontotemporal pathology in subsets of primary progressive aphasia. Ann Neurol 2008; 63:709-19.

59. Deramecourt V, Lebert F, Debachy B, et al. Prediction of pathology in primary progressive language and speech disorders. Neurology 2010;74:42-9.

60. Hu WT, McMillan C, Libon D, et al. Multimodal predictors for Alzheimer disease in nonfluent primary progressive aphasia. Neurology 2010;75:595-602.

61. Amici S, Gorno-Tempini ML, Ogar JM, et al. An overview on primary progressive aphasia and its variants. Behav Neurol 2006:17:77-87.

62. Brambati SM, Ogar J, Neuhaus J, et al. Reading disorders in primary progressive aphasia: a behavioral and neuroimaging study. Neuropsychologia 2009:47:1893-900.

63. Rohrer JD, Ridgway GR, Crutch SJ, et al. Progressive logopenic/phonological aphasia: erosion of the language network. Neuroimage 2010;49:984-93.

64. Wilson SM, Henry ML, Besbris M, et al. Connected speech production in three variants of primary progressive aphasia. Brain 2010;133:2069-88.

65. Seelaar H, Schelhaas HJ, Azmani A, et al. TDP-43 pathology in familial frontotemporal dementia and motor neuron disease without Progranulin mutations. Brain 2007;130:1375-85.

66 . Lomen-Hoerth C. Anderson T, Miller B. The overlap of amyotrophic lateral sclerosis and frontotemporal dementia. Neurology 2002;59:1077-9.

67. Chan D, Anderson V, Pijnenburg Y, et al. The clinical profile of right temporal lobe atrophy. Brain 2009:132:1287-98.

68. Josephs KA, Whitwell JL, Knopman DS, et al. Two distinct subtypes of right temporal variant frontotemporal dementia. Neurology 2009;73:1443-50.

69. Gregory CA, Hodges JR. Clinical features of frontal lobe dementia in comparison to Alzheimer's disease. J Neural Transm 1996;47:103-23.

70. Diehl-Schmid J, Pohl C, Perneczky R, et al. Behavioral disturbances in the course of frontotemporal dementia. Dementia Geriatr Cogn Disord 2006;22:352-7.

71. Hodges JR, Patterson K, Ward R, et al. The differentiation of semantic dementia and frontal lobe dementia (temporal and frontal variants of frontotemporal dementia) from early Alzheimer's disease: a comparative neuropsychological study. Neuropsychology 1999;13:31-40.

72. Kramer JH, Jurik J, Sha SJ, et al. Distinctive neuropsychological patterns in frontotemporal dementia, semantic dementia, and Alzheimer disease. Cogn Behav Neurol 2003:16:211-18.

73. Libon DJ, Xie SX, Wang X, et al. Neuropsychological decline in frontotemporal lobar degeneration: a longitudinal analysis. Neuropsychology 2009;23:337-46.

74. Wittenberg D, Possin KL, Rascovsky K, et al. The early neuropsychological and behavioral characteristics of frontotemporal dementia. Neuropsychol Rev 2008;18:91-102. 
75. Snowden JS, Gibbons ZC, Blackshaw A, et al. Social cognition in frontotemporal dementia and Huntington's disease. Neuropsychologia 2003;41:688-701.

76. Rogers TT, Ivanoiu A, Patterson K, et al. Semantic memory in Alzheimer's disease and the frontotemporal dementias: a longitudinal study of 236 patients. Neuropsychology 2006;20:319-35.

77. Rascovsky K, Salmon DP, Hansen LA, et al. Disparate letter and semantic category fluency deficits in autopsy-confirmed frontotemporal dementia and Alzheimer's disease. Neuropsychology 2007;21:20-30

78. Libon DJ, McMillan C, Gunawardena D, et al. Neurocognitive contributions to verbal fluency deficits in frontotemporal lobar degeneration. Neurology 2009;73:535-42.

79. Hodges JR, Davies RR, Xuereb JH, et al. Clinicopathological correlates in frontotemporal dementia. Ann Neurol 2004;56:399-406.

80. van Swieten JC, Heutink P. Mutations in progranulin (GRN) within the spectrum of clinical and pathological phenotypes of frontotemporal dementia. Lancet Neurol 2008; 7:965-74

81. Hornberger $\mathbf{M}$, Piguet 0 , Graham AJ, et al. How preserved is episodic memory in behavioral variant frontotemporal dementia? Neurology 2010;74:472-9.

82. Nedjam Z, Devouche E, Dalla Barba G. Confabulation, but not executive dysfunction discriminate AD from frontotemporal dementia. Eur J Neurol 2004:11:728-33.

83. Hutchinson AD, Mathias JL. Neuropsychological deficits in frontotemporal dementia and Alzheimer's disease: a meta-analytic review. J Neurol Neurosurg Psychiatry 2007;78:917-28.

84. Collette $\mathbf{F}$, Amieva H, Adam S, et al. Comparison of inhibitory functioning in mild Alzheimer's disease and frontotemporal dementia. Cortex 2007:43:866-74.

85. Lough S, Kipps CM, Treise C, et al. Social reasoning, emotion and empathy in frontotemporal dementia. Neuropsychologia 2006;44:950-8.

86. Rosen HJ, Wilson MR, Schauer GF, et al. Neuroanatomical correlates of impaired recognition of emotion in dementia. Neuropsychologia 2006;44:365-73

87. Lavenu I, Pasquier F. Perception of emotion on faces in frontotemporal dementia and Alzheimer's disease: a longitudinal study. Dementia Geriatr Cogn Disord 2005; 19:37-41

88. Fernandez-Duque D, Black SE. Impaired recognition of negative facial emotions in patients with frontotemporal dementia. Neuropsychologia 2005:43:1673-87.

89. Keane J, Calder AJ, Hodges JR, et al. Face and emotion processing in frontal variant frontotemporal dementia. Neuropsychologia 2002:40:655-65

90. Kipps CM, Mioshi E, Hodges JR. Emotion, social functioning and activities of daily living in frontotemporal dementia. Neurocase 2009;15:182-9.

91. Mendez MF, McMurtray A, Licht E, et al. The scale for emotional blunting in patients with frontotemporal dementia. Neurocase 2006;12:242-6.

92. Broe M, Hodges JR, Schofield E, et al. Staging disease severity in pathologically confirmed cases of frontotemporal dementia. Neurology 2003; 60:1005-11.

93. Eslinger PJ, Moore P, Troiani V, et al. Oops! Resolving social dilemmas in frontotemporal dementia. J Neurol Neurosurg Psychiatry 2007:78:457-60.

94. Adenzato M, Cavallo M, Enrici I. Theory of mind ability in the behavioural variant of frontotemporal dementia: an analysis of the neural, cognitive, and social levels. Neuropsychologia 2010;48:2-12.

95. Gregory C, Lough S, Stone V, et al. Theory of mind in patients with frontal variant frontotemporal dementia and Alzheimer's disease: theoretical and practical implications. Brain 2002;125:752-64.

96. Rankin KP, Kramer JH, Miller BL. Patterns of cognitive and emotional empathy in frontotemporal lobar degeneration. Cogn Behav Neurol 2005;18:28-36.

97. Lavenu I, Pasquier $F$, Lebert $F$, et al. Perception of emotion in frontotemporal dementia and Alzheimer disease. Alzheimer Dis Assoc Disord 1999:13:96-101.

98. Sturm VE, Rosen HJ, Allison S, et al. Self-conscious emotion deficits in frontotemporal lobar degeneration. Brain 2006;129:2508-16.

99. Sturm VE, Ascher EA, Miller BL, et al. Diminished self-conscious emotional responding in frontotemporal lobar degeneration patients. Emotion 2008;8:861-9.

100. Rohrer JD, Warren JD, Barnes J, et al. Mapping the progression of progranulinassociated frontotemporal lobar degeneration. Nat Clin Pract Neurol 2008:4:455-60.

101. Seeley WW, Crawford R, Rascovsky K, et al. Frontal paralimbic network atrophy in very mild behavioral variant frontotemporal dementia. Arch Neurol 2008;65:249-55.

102. Schroeter ML, Raczka K, Neumann J, et al. Neural networks in frontotemporal dementia-a meta-analysis. Neurobiol Aging 2008;29:418-26.

103. Seelaar $\mathbf{H}$, Klijnsma KY, de Koning I, et al. Frequency of ubiquitin and FUS-positive, TDP-43-negative frontotemporal lobar degeneration. J Neurol 2010;257:747-53.

104. Josephs KA, Whitwell JL, Parisi JE, et al. Caudate atrophy on MRI is a characteristic feature of FTLD-FUS. Eur J Neurol 2010;17:969-75.

105. Rohrer JD, Ridgway GR, Modat M, et al. The clinical and neuroanatomical phenotype of FUS-associated frontotemporal lobar degeneration. J Neurol Neurosurg Psychiatry. Published Online First: 16 July 2010

106. Rohrer JD, Ridgway GR, Modat M, et al. Distinct profiles of brain atrophy in frontotemporal lobar degeneration caused by progranulin and tau mutations. Neuroimage 2010;53:1070-6.

107. Whitwell JL, Jack CR Jr, Boeve BF, et al. Voxel-based morphometry patterns of atrophy in FTLD with mutations in MAPT or PGRN. Neurology 2009;72:813-20.

108. Cruchaga C, Fernandez-Seara MA, Seijo-Martinez M, et al. Cortical atrophy and language network reorganization associated with a novel progranulin mutation. Cereb Cortex 2009;19:1751-60.
109. Whitwell JL, Jack CR Jr, Boeve BF, et al. Atrophy patterns in IVS10+16, IVS10 +3 , N279K, S305N, P301L, and V337M MAPT mutations. Neurology 2009; 73:1058-65

110. Whitwell JL, Przybelski SA, Weigand SD, et al. Distinct anatomical subtypes of the behavioural variant of frontotemporal dementia: a cluster analysis study. Brain 2009:132:2932-46.

111. Mummery CJ, Patterson K, Wise RJ, et al. Disrupted temporal lobe connections in semantic dementia. Brain 1999;122:61-73.

112. Mummery CJ, Patterson K, Price CJ, et al. A voxel-based morphometry study of semantic dementia: relationship between temporal lobe atrophy and semantic memory. Ann Neurol 2000;47:36-45.

113. Chan D, Fox NC, Scahill Rl, et al. Patterns of temporal lobe atrophy in semantic dementia and Alzheimer's disease. Ann Neurol 2001;49:433-42.

114. Galton CJ, Patterson K, Graham K, et al. Differing patterns of temporal atrophy in Alzheimer's disease and semantic dementia. Neurology 2001:57:216-25.

115. Rohrer JD, Warren JD, Modat M, et al. Patterns of cortical thinning in the language variants of frontotemporal lobar degeneration. Neurology 2009;72:1562-9.

116. Rohrer JD, McNaught E, Foster J, et al. Tracking progression in frontotemporal lobar degeneration: serial MRI in semantic dementia. Neurology 2008;71 $1445-51$

117. Brambati SM, Rankin KP, Narvid J, et al. Atrophy progression in semantic dementia with asymmetric temporal involvement: a tensor-based morphometry study. Neurobiology Aging 2009;30:103-11.

118. Pereira JM, Williams GB, Acosta-Cabronero J, et al. Atrophy patterns in histologic vs clinical groupings of frontotemporal lobar degeneration. Neurology 2009; 72:1653-60.

119. Ogar JM, Dronkers NF, Brambati SM, et al. Progressive nonfluent aphasia and its characteristic motor speech deficits. Alzheimer Dis Assoc Disord 2007;21: S23-30.

120. Nestor PJ, Graham NL, Fryer TD, et al. Progressive non-fluent aphasia is associated with hypometabolism centred on the left anterior insula. Brain 2003;126:2406-18

121. Looi JC, Lindberg 0, Zandbelt BB, et al. Caudate nucleus volumes in frontotempora lobar degeneration: differential atrophy in subtypes. Am J Neuroradiol 2008:29:1537-43.

122. Josephs KA, Duffy JR, Strand EA, et al. Clinicopathological and imaging correlates of progressive aphasia and apraxia of speech. Brain 2006;129:1385-98.

123. Rohrer JD, Paviour D, Bronstein AM, et al. Progressive supranuclear palsy syndrome presenting as progressive nonfluent aphasia: a neuropsychological and neuroimaging analysis. Mov Disord 2010;25:179-88

124. Lehmann M, Rohrer JD, Clarkson MJ, et al. Reduced cortical thickness in the posterior cingulate gyrus is characteristic of both typical and atypical Alzheimer's disease. J Alzheimers Dis 2010;20:587-98.

125. Whitwell JL, Jack CR Jr, Przybelski SA, et al. Temporoparietal atrophy: a marker of $\mathrm{AD}$ pathology independent of clinical diagnosis. Neurobiol Aging. Published Online First: 13 November 2009

126. Migliaccio R, Agosta F, Rascovsky K, et al. Clinical syndromes associated with posterior atrophy: early age at onset $\mathrm{AD}$ spectrum. Neurology 2009:73:1571-8.

127. Davies RR, Scahill VL, Graham A, et al. Development of an MRI rating scale for multiple brain regions: comparison with volumetrics and with voxel-based morphometry. Neuroradiology 2009;51:491-503.

128. Kloppel S, Stonnington CM, Chu C, et al. Automatic classification of MR scans in Alzheimer's disease. Brain 2008;131:681-9.

129. Avants BB, Cook PA, Ungar L, et al. Dementia induces correlated reductions in white matter integrity and cortical thickness: a multivariate neuroimaging study with sparse canonical correlation analysis. Neuroimage 2010:50:1004-16.

130. Hu WT, Wang Z, Lee VM-Y, et al. Distinct cerebral perfusion patterns in FTLD and AD. Neurology 2010;75:881-8.

131. Rabinovici GD, Furst AJ, O'Neil JP, et al. 11C-PIB PET imaging in Alzheimer disease and frontotemporal lobar degeneration. Neurology 2007;68:1205-12.

132. Seeley WW, Crawford RK, Zhou J, et al. Neurodegenerative diseases target largescale human brain networks. Neuron 2009:62:42-52.

133. Zhou J, Greicius MD, Gennatas ED, et al. Divergent network connectivity changes in behavioural variant frontotemporal dementia and Alzheimer's disease. Brain 2010;133:1352-67.

134. Seeley WW, Carlin DA, Allman JM, et al. Early frontotemporal dementia targets neurons unique to apes and humans. Ann Neurol 2006:60:660-7.

135. Verwey NA, Kester Ml, van der Flier WM, et al. Additional value of CSF amyloidbeta 40 levels in the differentiation between FTLD and control subjects. $J$ Alzheimers Dis 2010:20:445-52.

136. Coppola G, Karydas A, Rademakers R, et al. Gene expression study on periphera blood identifies progranulin mutations. Ann Neurol 2008:64:92-6.

137. Finch N, Baker M, Crook R, et al. Plasma progranulin levels predict progranulin mutation status in frontotemporal dementia patients and asymptomatic family members. Brain 2009;132:583-91.

138. Ghidoni R, Benussi L, Glionna M, et al. Low plasma progranulin levels predict progranulin mutations in frontotemporal lobar degeneration. Neurology 2008:71:1235-9.

139. Sleegers K, Brouwers N, Van Damme P, et al. Serum biomarker for progranulinassociated frontotemporal lobar degeneration. Ann Neurol 2009;65:603-9. 
140. Carecchio M, Fenoglio C, De Riz M, et al. Progranulin plasma levels as potential biomarker for the identification of GRN deletion carriers. A case with atypical onset as clinical amnestic Mild Cognitive Impairment converted to Alzheimer's disease. J Neurol Sciences 2009;287:291-3.

141. Steinacker $\mathbf{P}$, Hendrich C, Sperfeld AD, et al. TDP-43 in cerebrospinal fluid of patients with frontotemporal lobar degeneration and amyotrophic lateral sclerosis. Arch Neurol 2008;65:1481-7.

142. Foulds PG, Davidson Y, Mishra M, et al. Plasma phosphorylated-TDP-43 protein levels correlate with brain pathology in frontotemporal lobar degeneration. Acta Neuropathol 2009;118:647-58.

143. Hu WT, Chen-Plotkin A, Arnold SE, et al. Biomarker discovery for Alzheimer's disease, frontotemporal lobar degeneration, and Parkinson's disease. Acta Neuropathol 2010;120:385-99.

144. Hu WT, Chen-Plotkin A, Grossman M, et al. Novel CSF biomarkers for frontotemporal lobar degeneration. Neurology Published Online First: November 3 2010. doi:10.1212/WNL.0b013e318200d78d.

145. Stevens M, van Duijn CM, Kamphorst W, et al. Familial aggregation in frontotemporal dementia. Neurology 1998;50:1541-5

146. Rohrer JD, Guerreiro R, Vandrovcova J, et al. The heritability and genetics of frontotemporal lobar degeneration. Neurology 2009:73:1451-6.

147. Goedert M, Spillantini MG, Jakes $\mathrm{R}$, et al. Multiple isoforms of human microtubuleassociated protein tau: sequences and localization in neurofibrillary tangles of Alzheimer's disease. Neuron 1989:3:519-26.

148. Goedert M, Spillantini MG, Potier MC, et al. Cloning and sequencing of the CDNA encoding an isoform of microtubule-associated protein tau containing four tandem repeats: differential expression of tau protein mRNAs in human brain. EMBO $J$ 1989;8:393-9.

149. van Swieten J, Spillantini MG. Hereditary frontotemporal dementia caused by Tau gene mutations. Brain Pathol 2007;17:63-73.

150. Boeve BF, Hutton M. Refining frontotemporal dementia with parkinsonism linked to chromosome 17: introducing FTDP-17 (MAPT) and FTDP-17 (PGRN). Arch Neurol 2008; 65:460-4.

151. Gass J, Cannon A, Mackenzie IR, et al. Mutations in progranulin are a major cause of ubiquitin-positive frontotemporal lobar degeneration. Hum Mol Genet 2006;15:2988-3001.

152. Le Ber I, van der Zee J, Hannequin D, et al. Progranulin null mutations in both sporadic and familial frontotemporal dementia. Hum Mutat 2007;28:846-55.

153. Pickering-Brown SM, Baker M, Gass J, et al. Mutations in progranulin explain atypical phenotypes with variants in MAPT. Brain 2006:129:3124-6.

154. Ahmed Z, Mackenzie IR, Hutton ML, et al. Progranulin in frontotemporal lobar degeneration and neuroinflammation. J Neuroinflammation 2007:4:7.

155. Mackenzie IR, Baker M, Pickering-Brown S, et al. The neuropathology of frontotemporal lobar degeneration caused by mutations in the progranulin gene. Brain 2006;129:3081-90.

156. Mesulam M, Johnson N, Krefft TA, et al. Progranulin mutations in primary progressive aphasia: the PPA1 and PPA3 families. Arch Neurol 2007;64:43-7.

157. Le Ber I, Camuzat A, Hannequin D, et al. Phenotype variability in progranulin mutation carriers: a clinical, neuropsychological, imaging and genetic study. Brain 2008;131:732-46.

158. Benussi L, Binetti G, Sina $\mathrm{E}$, et al. A novel deletion in progranulin gene is associated with FTDP-17 and CBS. Neurobiol Aging 2008;29:427-35.

159. Boeve BF, Baker M, Dickson DW, et al. Frontotemporal dementia and parkinsonism associated with the IVS1+1G->A mutation in progranulin: a clinicopathologic study. Brain 2006;129:3103-14.

160. Josephs KA, Ahmed Z, Katsuse 0, et al. Neuropathologic features of frontotemporal lobar degeneration with ubiquitin-positive inclusions with progranulin gene (PGRN) mutations. J Neuropathol Exp Neurol 2007;66:142-51.

161. Kelley BJ, Haidar W, Boeve BF, et al. Prominent phenotypic variability associated with mutations in Progranulin. Neurobiol Aging 2009;30:739-51.

162. Rademakers R, Baker M, Gass J, et al. Phenotypic variability associated with progranulin haploinsufficiency in patients with the common 1477C->T (Arg493X) mutation: an international initiative. Lancet Neurol 2007;6:857-68.

163. Beck J, Rohrer JD, Campbell T, et al. A distinct clinical, neuropsychological and radiological phenotype is associated with progranulin gene mutations in a large UK series. Brain 2008:131:706-20.

164. Masellis M, Momeni P, Meschino W, et al. Novel splicing mutation in the progranulin gene causing familial corticobasal syndrome. Brain 2006;129:3115-23.

165. Rohrer JD, Warren JD, Omar R, et al. Parietal lobe deficits in frontotemporal lobar degeneration caused by a mutation in the progranulin gene. Arch Neurol 2008;65:506-13

166. Pickering-Brown SM, Rollinson S, Du Plessis D, et al. Frequency and clinical characteristics of progranulin mutation carriers in the Manchester frontotemporal lobar degeneration cohort: comparison with patients with MAPT and no known mutations. Brain 2008:131:721-31.

167. Mackenzie IR, Baker M, West G, et al. A family with tau-negative frontotemporal dementia and neuronal intranuclear inclusions linked to chromosome 17. Brain 2006;129:853-67.

168. Watts GD, Wymer J, Kovach MJ, et al. Inclusion body myopathy associated with Paget disease of bone and frontotemporal dementia is caused by mutant valosincontaining protein. Nat Genet 2004:36:377-81.

169. Skibinski G, Parkinson NJ, Brown JM, et al. Mutations in the endosomal ESCRTIIIcomplex subunit CHMP2B in frontotemporal dementia. Nat Genet 2005;37:806-8.
170. Benajiba L, Le Ber I, Camuzat A, et al. TARDBP mutations in motoneuron disease with frontotemporal lobar degeneration. Ann Neurol 2009;65:470-3.

171. Borroni B, Bonvicini C, Alberici A, et al. Mutation within TARDBP leads to frontotemporal dementia without motor neuron disease. Human Mutat 2009;30:E974-83

172. Kimonis VE, Fulchiero E, Vesa J, et al. VCP disease associated with myopathy, Paget disease of bone and frontotemporal dementia: review of a unique disorder Biochim Biophys Acta 2008;1782:744-8.

173. Gydesen S, Brown JM, Brun A, et al. Chromosome 3 linked frontotemporal dementia (FTD-3). Neurology 2002;59:1585-94

174. Parkinson N, Ince PG, Smith MO, et al. ALS phenotypes with mutations in CHMP2B (charged multivesicular body protein 2B). Neurology 2006:67:1074-7.

175. Yokoseki A, Shiga A, Tan CF, et al. TDP-43 mutation in familial amyotrophic latera sclerosis. Ann Neurol 2008;63:538-42.

176. Gitcho MA, Baloh RH, Chakraverty S, et al. TDP-43 A315T mutation in familial motor neuron disease. Ann Neurol 2008;63:535-8.

177. Sreedharan J, Blair IP, Tripathi VB, et al. TDP-43 mutations in familial and sporadic amyotrophic lateral sclerosis. Science 2008;319:1668-72.

178. Daoud H, Valdmanis PN, Kabashi E, et al. Contribution of TARDBP mutations to sporadic amyotrophic lateral sclerosis. J Med Genet 2009:46:112-14.

179. Kabashi E, Valdmanis PN, Dion P, et al. TARDBP mutations in individuals with sporadic and familial amyotrophic lateral sclerosis. Nat Genet 2008;40:572-4.

180. Kuhnlein P, Sperfeld AD, Vanmassenhove B, et al. Two German kindreds with familial amyotrophic lateral sclerosis due to TARDBP mutations. Arch Neurol 2008:65:1185-9.

181. Rutherford NJ, Zhang YJ, Baker M, et al. Novel mutations in TARDBP (TDP-43) in patients with familial amyotrophic lateral sclerosis. PLoS Genet 2008;4:e1000193.

182. Van Deerlin VM, Leverenz JB, Bekris LM, et al. TARDBP mutations in amyotrophic lateral sclerosis with TDP-43 neuropathology: a genetic and histopathological analysis. Lancet Neurol 2008;7:409-16.

183. Vance C, Rogelj B, Hortobagyi T, et al. Mutations in FUS, an RNA processing protein, cause familial amyotrophic lateral sclerosis type 6 . Science 2009;323:1208-11.

184. Kwiatkowski TJ Jr, Bosco DA, Leclerc AL, et al. Mutations in the FUS/TLS gene on chromosome 16 cause familial amyotrophic lateral sclerosis. Science 2009; 323:1205-8.

185. Chio A, Restagno G, Brunetti M, et al. Two Italian kindreds with familial amyotrophic lateral sclerosis due to FUS mutation. Neurobiol Aging 2009:30:1272-5.

186. Groen EJ, van Es MA, van Vught PW, et al. FUS mutations in familial amyotrophic lateral sclerosis in The Netherlands. Arch Neurol 2010;67:224-30.

187. Van Langenhove T, van der Zee J, Sleegers $\mathrm{K}$, et al. Genetic contribution of FUS to frontotemporal lobar degeneration. Neurology 2010;74:366-71.

188. Le Ber I, Camuzat A, Berger E, et al. Chromosome 9p-linked families with frontotemporal dementia associated with motor neuron disease. Neurology 2009;72:1669-76.

189. Vance C, Al-Chalabi A, Ruddy D, et al. Familial amyotrophic lateral sclerosis with frontotemporal dementia is linked to a locus on chromosome 9p13.2-21.3. Brain 2006; 129:868-76.

190. Morita M, Al-Chalabi A, Andersen PM, et al. A locus on chromosome 9p confers susceptibility to ALS and frontotemporal dementia. Neurology 2006;66:839-44.

191. Momeni P, Schymick J, Jain S, et al. Analysis of IFT74 as a candidate gene for chromosome 9p-linked ALS-FTD. BMC Neurol 2006;6:44

192. Valdmanis PN, Dupre N, Bouchard JP, et al. Three families with amyotrophic lateral sclerosis and frontotemporal dementia with evidence of linkage to chromosome 9p. Arch Neurol 2007;64:240-5.

193. Luty AA, Kwok JB, Thompson EM, et al. Pedigree with frontotemporal lobar degeneration-motor neuron disease and Tar DNA binding protein-43 positive neuropathology: genetic linkage to chromosome 9. BMC Neurol 2008:8:32.

194. Rademakers R, Eriksen JL, Baker M, et al. Common variation in the miR-659 binding-site of GRN is a major risk factor for TDP43-positive frontotemporal dementia. Hum Mol Genet 2008:17:3631-42.

195. Simon-Sanchez J, Seelaar H, Bochdanovits Z, et al. Variation at GRN 3'-UTR rs5848 is not associated with a risk of frontotemporal lobar degeneration in Dutch population. PloS One 2009;4:e7494.

196. Rollinson S, Rohrer JD, van der Zee J. No association of PGRN 3'UTR rs5848 in frontotemporal lobar degeneration. Neurobiol Aging 2011;32:754-5.

197. Verpillat P, Camuzat A, Hannequin D, et al. Apolipoprotein E gene in frontotemporal dementia: an association study and meta-analysis. Eur J Hum Genet 2002: 10:399-405.

198. Srinivasan R, Davidson Y, Gibbons L, et al. The apolipoprotein E epsilon4 allele selectively increases the risk of frontotemporal lobar degeneration in males. J Neurol Neurosurg Psychiatry 2006;77:154-8.

199. Rohrer JD, Mead S, Omar R, et al. Prion protein (PRNP) genotypes in frontotempora lobar degeneration syndromes. Ann Neurol 2006;60:616; author reply 7.

200. Li X, Rowland LP, Mitsumoto H, et al. Prion protein codon 129 genotype prevalence is altered in primary progressive aphasia. Ann Neurol 2005: 58:858-64.

201. Benussi L, Ghidoni R, Galimberti D, et al. The CST3 B haplotype is associated with frontotemporal lobar degeneration. Eur J Neurol 2010;17:143-6. 
202. Rollinson S, Rizzu P, Sikkink S, et al. Ubiquitin associated protein 1 is a risk factor for frontotemporal lobar degeneration. Neurobiol Aging 2009;30:656-65.

203. Van Deerlin VM, Sleiman PMA, Martinez-Lage M, et al. Common genetic variants at 7p21 show strong association with frontotemporal lobar degeneration with TDP-43 inclusions. Nat Genet 2010;42:234-9.

204. Neumann M, Sampathu DM, Kwong LK, et al. Ubiquitinated TDP-43 in frontotemporal lobar degeneration and amyotrophic lateral sclerosis. Science 2006;314:130-3.

205. Josephs KA, Lin WL, Ahmed Z, et al. Frontotemporal lobar degeneration with ubiquitin-positive, but TDP-43-negative inclusions. Acta Neuropathol 2008;116:159-67.

206. Mackenzie IR, Foti D, Woulfe J, et al. Atypical frontotemporal lobar degeneration with ubiquitin-positive, TDP-43-negative neuronal inclusions. Brain 2008;131:1282-93.
207. Roeber S, Mackenzie IR, Kretzschmar HA et al. TDP-43-negative FTLD-U is a significant new clinico-pathological subtype of FTLD. Acta Neuropathol 2008;116:147-57.

208. Urwin H, Josephs KA, Rohrer JD, et al. FUS pathology defines the majority of tauand TDP-43-negative frontotemporal lobar degeneration. Acta Neuropathol 2010;120:33-41.

209. Neumann M, Roeber S, Kretzschmar HA, et al. Abundant FUS-immunoreactive pathology in neuronal intermediate filament inclusion disease. Acta Neuropathol 2009:118:605-16

210. Holm IE, Isaacs AM, Mackenzie IR. Absence of FUS-immunoreactive pathology in frontotemporal dementia linked to chromosome 3 (FTD-3) caused by mutation in the CHMP2B gene. Acta Neuropathol 2009:118:719-20.

211. Mioshi E, Hsieh S, Savage S, et al. Clinical staging and disease progression in frontotemporal dementia. Neurology 2010;74:1591-7.

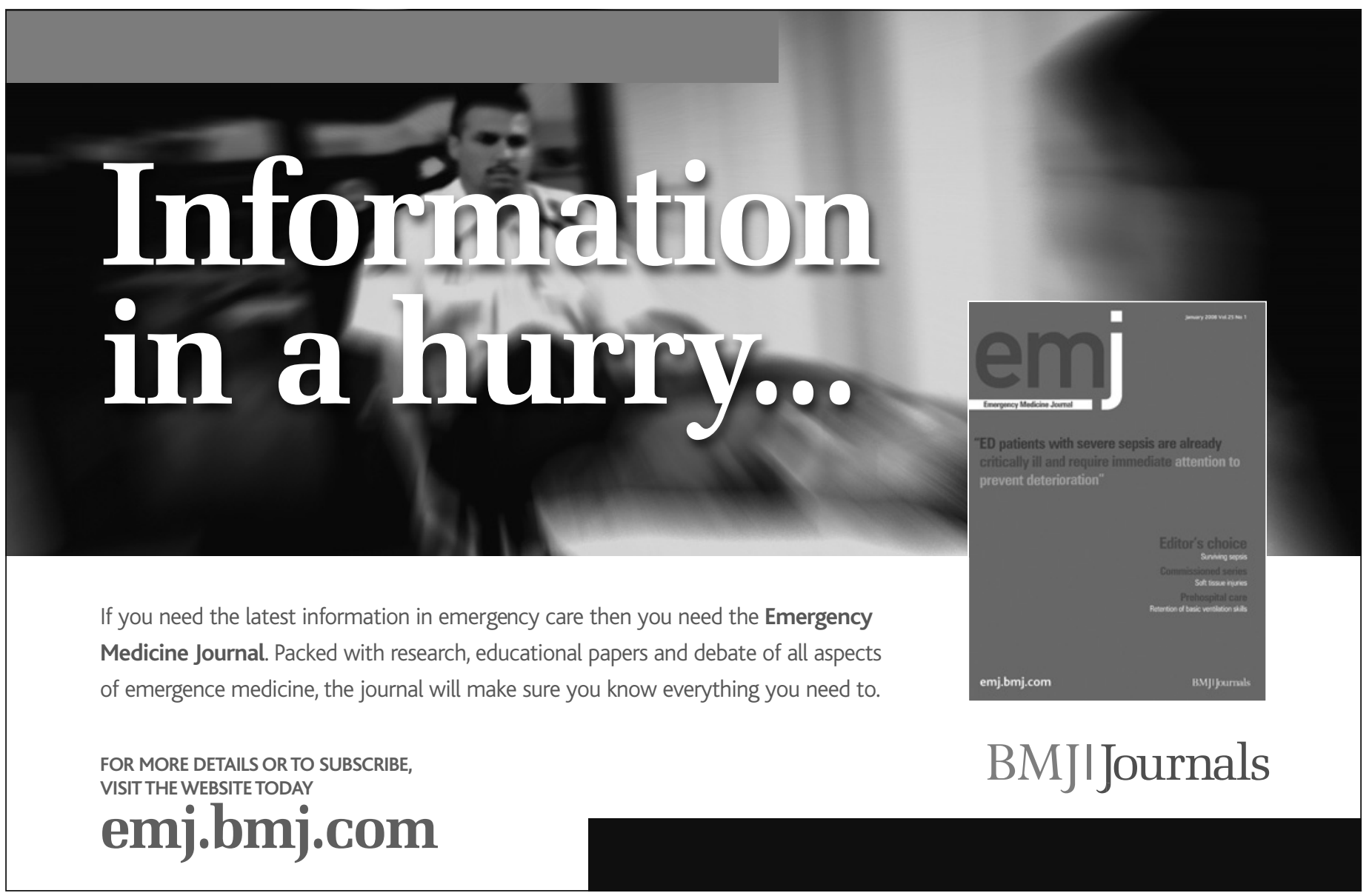

